\title{
Electrochemical Ozone Generation Using Compacted High Pressure High Temperature Boron Doped Diamond Microparticle Electrodes
}

Georgia F. Wood, Irina M. Terrero Rodríguez, Joshua J. Tully, Shayantan Chaudhuri and Julie V. Macpherson*

\begin{abstract}
Electrochemical ozone production (EOP) from water is an attractive, green technology for disinfection. Boron doped diamond (BDD) electrodes, grown by chemical vapor deposition (CVD), have been widely adopted for EOP due to their wide anodic window in water and excellent chemical and electrochemical stability. High pressure high temperature (HPHT) synthesis, an alternative growth technique used predominantly for the high-volume synthesis of nitrogen doped diamond microparticles, has been seldom employed for the production of conductive BDD electrodes. In this letter, we demonstrate, for the first time, the use of BDD electrodes fabricated from HPHT conductive BDD microparticles for EOP. The BDD microparticles are first compacted to produce freestanding solid electrodes and then laser micromachined to produce a perforated electrode. The HPHT BDD electrodes are shown to exhibit high EOP, producing $2.23 \pm 0.07 \mathrm{mg} \mathrm{L}^{-1}$ of ozone per ampere of current, at consistent levels for a continuous $20 \mathrm{hr}$ period with no drop off in performance.
\end{abstract}

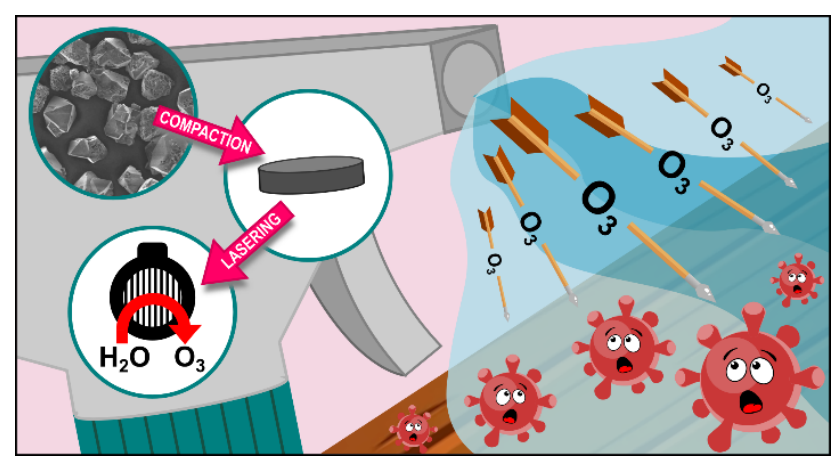




\section{Introduction}

Dissolved ozone in water is an environmentally clean and powerful oxidant, with an absence of harmful residues, which has found use in sterilization/sanitization, ${ }^{1}$ deodorization, ${ }^{2}$ decolorization, ${ }^{3}$ and the treatment of potable water/wastewater. ${ }^{4,5}$ As ozone decays in water with a half-life of ca. 20 minutes, ${ }^{4}$ production on-site is a necessity. Traditionally, ozone is produced in air (or oxygen) via corona discharge, under very high voltages. ${ }^{6}$ This process is energy intensive, requires a high initial cost, and produces large amounts of heat and also harmful nitrogen oxides (in air). ${ }^{7-9}$ In contrast, electrochemical ozone production (EOP) has gained much attention as dissolved ozone can be produced simply by oxidizing water at a suitable anode, with the advantages of a small-scale and robust experimental set-up, low voltage operation, high current efficiency and no gas feedstocks. ${ }^{10}$

Efficient EOP requires an anode that electrocatalytically favors EOP over the oxygen evolution reaction (OER). The electrode materials which have shown most promise are synthetic boron doped diamond (BDD), ${ }^{11-17} \mathrm{PbO}_{2},{ }^{18} \mathrm{TiO}_{2},{ }^{19}$ and $\mathrm{Ni} / \mathrm{Sb}$ doped $\mathrm{SnO}_{2} .{ }^{20} \mathrm{BDD}$ is particularly interesting as it presents no heavy metal contamination issues, exhibits a very wide anodic solvent window in water due to OER being disfavored and experiences minimal electrochemical corrosion during operation, unlike materials such as $\mathrm{PbO}_{2}$ and doped $\mathrm{SnO}_{2}{ }^{8}$

To date, to the best of our knowledge, all studies which use BDD employ material grown using either hot filament or microwave chemical vapor deposition (CVD). ${ }^{21,22}$ The BDD is either grown in thin film form, where it remains attached to the growth substrate, or thick enough so that it can be removed and is freestanding. Thin film $\mathrm{BDD}^{11-17}$ has been used for EOP with either water, ${ }^{13,14,17}$ sulfuric acid, ${ }^{11,12}$ or perchloric acid ${ }^{12}$ as the electrolyte. In water, a Nafion ${ }^{\circledR}$ separating membrane is essential, functioning as both a solid electrolyte and as a proton transporter. Perforated freestanding BDD electrodes have also been used in ozone generation, ${ }^{15,16}$ designed with an aim to maximize contact between BDD, solution and the 
Nafion ${ }^{\circledR}$ membrane. ${ }^{16}$ Freestanding BDD electrodes offer the advantages of superior robustness, higher efficiency, durability and stability over long time periods. Thin film BDD electrodes can delaminate and develop pin holes. ${ }^{23-25}$

An alternative more scalable method to producing large volumes of synthetic diamond quickly is the use of high pressure high temperature (HPHT) synthesis. The global HPHT industry produces up to tens of tons per year of sub-mm sized diamond particles. ${ }^{26}$ However, unlike CVD, HPHT growth typically leads to the diamond containing a few $100 \mathrm{ppm}$ of single substitutional nitrogen. ${ }^{27}$ Nitrogen as a charge donor will compensate boron (charge acceptor) such that it can no longer contribute to charge transport. Thus, it is difficult to produce HPHT material with sufficient uncompensated boron to achieve metallic conductivity. Very recently, we introduced a method for the production of suitably conductive BDD HPHT microparticles using relatively mild HPHT conditions, ${ }^{28}$ where an aluminum diboride $\left(\mathrm{AlB}_{2}\right)$ boron source acted as a nitrogen sequester to reduce boron-nitrogen charge compensation.

In this letter, we explore for the first time, the use of conductive BDD HPHT microparticles as an electrode material suitable for EOP. The microparticles are compacted, under high pressure and temperature, to produce an electrode which, in form, resembles a solid freestanding material and can thus be processed accordingly. For the same cell design and operating conditions, the performance of the compacted HPHT BDD microparticle electrode, in terms of ozone outputs, efficiency, surface roughness and long-term stability, is compared against a freestanding CVD BDD electrode.

\section{Materials and Methods}

BDD electrodes: HPHT BDD microparticles were grown from a Fe/Ni/C melt with 4.8 $\mathrm{wt} \% \mathrm{AlB}_{2}$, producing microparticles with an uncompensated boron content of ca. $2-3 \times 10^{20} \mathrm{~B}$ atoms $\mathrm{cm}^{-3}{ }^{28}$ To produce a freestanding electrode, the HPHT microparticles were compacted 
under high pressure $(6.6 \mathrm{GPa})$ and high temperature $\left(1700{ }^{\circ} \mathrm{C}\right)$, using a cubic anvil press. This resulted in the production of cylindrical electrodes, with a circular diameter of ca. $16 \mathrm{~mm}$ and a thickness of $2 \mathrm{~mm}$. The four-point probe resistivity ${ }^{28}$ of the compact was measured as 540 $\mathrm{m} \Omega \mathrm{cm}$. To produce multiple electrodes $(\sim 500 \mu \mathrm{m}$ thickness $)$ the compact was sliced parallel to its circular ends using electrical discharge machining. The HPHT discs were either left "ascut" or mechanically abraded (lapped) to reduce the surface roughness. All electrodes were cleaned using a well-established acid treatment process. ${ }^{28-30}$ CVD electrode growth is described in ESI 1.

More detailed information on EOP cell design and construction is also given in ESI 1. Briefly, all ozone cells were 3D printed and comprised two individually addressable half cells accommodating one electrode each. Each half cell also contained a slot for a copper contact, and a path for parallel solution flow across the back of the electrodes. The two half cells were labelled A and B. Initially A was connected as the anode (for EOP) and B as the cathode. For some experiments the connection was reversed. Elastomeric gaskets were positioned in the main cell assembly and the two half cells bolted together with a Nafion ${ }^{\circledR}$ membrane sandwiched between them. The position of the Nafion ${ }^{\circledR}$ membrane with respect to the BDD electrode is shown in Fig. 1a. Fig. 1b is a photograph of one half cell prior to assembly and Fig. 1c shows the cross-sectional view through the assembled EOP cell, with the flow profile indicated for each half cell. Before measurements commenced an electrochemical pretreatment was utilized to hydrate and protonate the Nafion ${ }^{\circledR}$ membrane (ESI 2). Plots of applied current vs ozone concentration, referred to herein as calibration plots, were recorded over a current range of $0.1-0.6 \mathrm{~A}$ in approximately $0.1 \mathrm{~A}$ intervals. UV-Vis was employed for ozone quantification; described in full in ESI 1. 
a)

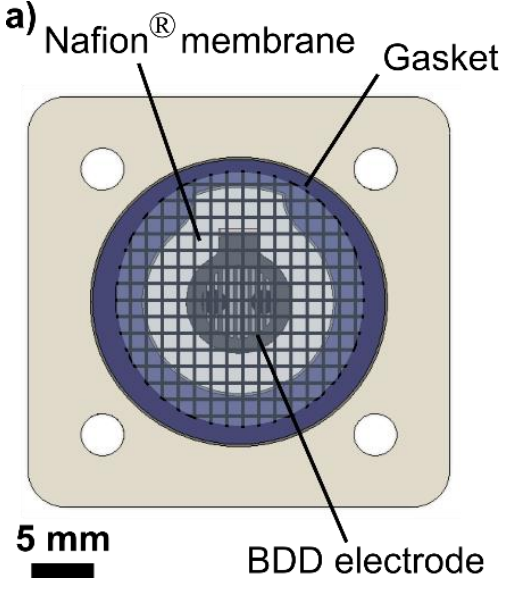

b)

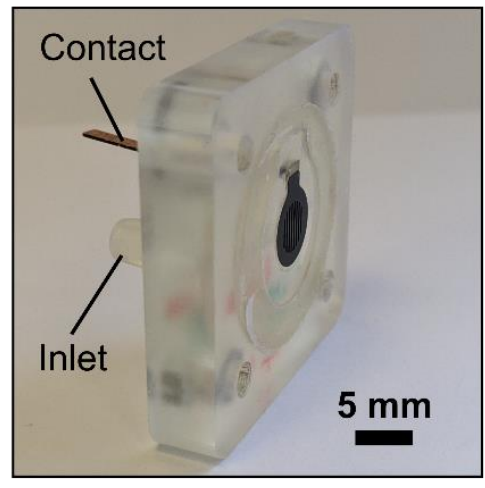

c) Nafion ${ }^{\circledR}$ membrane

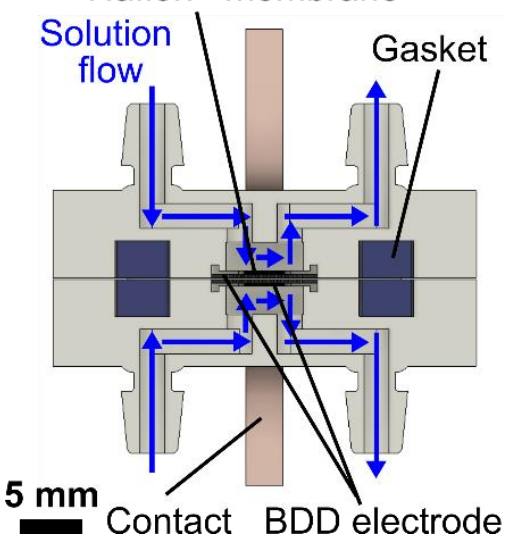

Figure 1: a) Render to show the front view of one half cell, b) photograph of one half cell (the contact and solution inlet can be seen at the back) prior to cell assembly, and c) render to show the flow profile and cross-sectional view through the assembled ozone generation cell.

\section{Results and Discussion}

Fig. 2a shows a typical microparticle compacted HPHT BDD freestanding EOP electrode. The electrode design was kept constant throughout and consists of an $8 \mathrm{~mm}$ diameter round containing 8 slots, $300 \mu \mathrm{m}$ wide, with each slot separated by $300 \mu \mathrm{m}$, cut with varying lengths to maintain a distance of $1 \mathrm{~mm}$ from the electrode perimeter. In total, the patterned area encompassed a $6 \mathrm{~mm}$ region of the electrode. As the Nafion ${ }^{\circledR}$ is compressed against the BDD surface, a slotted design was chosen in order to enable solution to come into contact with both the BDD and Nafion ${ }^{\circledR} .{ }^{14-16}$ Fig. 2a also importantly shows that the HPHT compaction conditions were sufficient to prevent the material disintegrating during lasering and mechanical abrasion.

a)

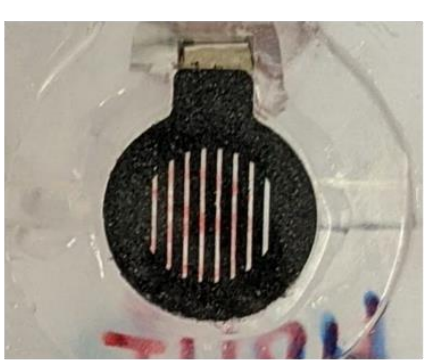

$4 \mathrm{~mm}$ b)

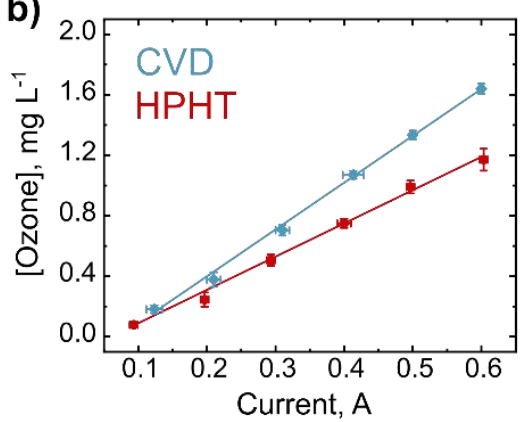

c)

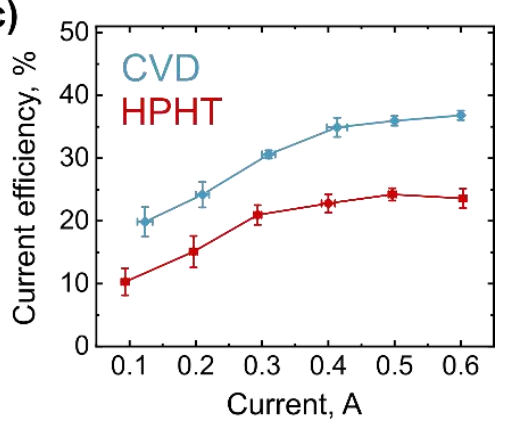


Figure 2: a) Photo of the compacted HPHT electrode laser cut into the desired geometry and adhered into a half cell. Also evident is the rectangular tab onto the back of which electrical contact is made. Plots show, b) dissolved ozone concentration versus applied current $(n=3)$ and c) current efficiency vs. applied current $(n=3)$ for the A side anode of the CVD BDD electrode cell (blue line) and the A side anode of the HPHT BDD electrode cell (red line). The flow rates were $335 \pm 4$ and $302 \pm 6 \mathrm{~mL} \mathrm{~min}^{-1}$ for the CVD and HPHT cells, respectively. Error bars represent one standard deviation.

For all experiments data was collected by combining the flow streams for anode and cathode (adopted due to ease of set-up). Fig. 2b displays the concentration of dissolved ozone produced for both the HPHT cell (red line) and the CVD cell (blue line), using distilled water, for applied currents in the range 0.1 A to 0.6 A. For each data point, the aliquot of solution for ozone analysis was taken when a stable voltage was reached after changing the applied current ( $30 \mathrm{~s})$. All calibration plots were run for $n=3$. For these studies, the Nafion®-contacted $\mathrm{A}$ face was always lower in surface roughness than the B face. Specifically for HPHT BDD the lapped as-cut surface (root mean squared (RMS) roughness $=3.4 \mu \mathrm{m}$ ) was used as the A face whilst the as-cut surface (RMS roughness $=6.1 \mu \mathrm{m}$ ) was used as the B face. For CVD BDD the lapped nucleation face (RMS roughness $=560 \mathrm{~nm}$ ) was used as the A face whilst the asgrown, growth face, $($ RMS roughness $=15.0 \mu \mathrm{m})$ was used as the B face. Interferometric measurements of surface roughness are provided in ESI 3.

For both cells, the amount of ozone generated can be seen to increase linearly as the applied current is increased, with ozone output gradients of $3.13 \pm 0.06$ and $2.23 \pm 0.07 \mathrm{mg} \mathrm{L}^{-}$ ${ }^{1}\left(1 \mathrm{mg} \mathrm{L}^{-1}=1 \mathrm{ppm}\right) \mathrm{A}^{-1}$ for the CVD and HPHT cells, respectively. The calibration plots show good linearity, with an adjusted $\mathrm{R}^{2}$ of 0.9945 for the CVD cell and 0.9882 for the HPHT cell. For the CVD cell, a maximum of $1.64 \pm 0.03 \mathrm{mg} \mathrm{L}^{-1}$ dissolved ozone was produced, at the highest applied current of $0.6 \mathrm{~A}$, compared to a maximum of $1.17 \pm 0.07 \mathrm{mg} \mathrm{L}^{-1}$ for the HPHT cell. The difference is most likely due to both the lower resistivity of the CVD electrodes (ca. 
$60 \mathrm{~m} \Omega \mathrm{cm}),{ }^{31}$ compared to the HPHT electrodes $(540 \mathrm{~m} \Omega \mathrm{cm})$ and increased solution resistance associated with the HPHT electrode due to solution confined within pores in the surface. ${ }^{28}$ In the CVD material the grains inter-grow during synthesis forming a non-porous material, resulting in good electrical connectivity. In contrast, HPHT compaction leads to the presence of sub-microscopic voids both between neighboring particles within the material, and at the surface of the compacted electrode. ${ }^{28}$ The impact of surface roughness is discussed below.

The current efficiency $(\varepsilon)$, in $\%$, of the EOP process was calculated using eq. 1 :

$$
\varepsilon=2 \times \frac{100 \times n F v C}{i M}
$$

where $n$ is the stoichiometric number of electrons transferred $(n=6)^{13}, F$ is the Faraday constant in $\mathrm{C} \mathrm{mol}^{-1}, v$ is the solution flow rate in $\mathrm{L} \mathrm{s}^{-1}, C$ is the concentration of dissolved ozone in mol $\mathrm{L}^{-1}, i$ is the applied current in $\mathrm{A}$, and $M$ is the molecular weight in $\mathrm{g} \mathrm{mol}^{-1} \cdot{ }^{16} \mathrm{~A}$ factor of two was introduced in the current efficiency equation to account for the combined anode/cathode flow streams. Fig. 2c compares the current efficiencies between the HPHT and CVD cells for the different applied currents. For both, the current efficiency increases with applied current from 0.1 to $0.3 \mathrm{~A}$. Between 0.4 and $0.6 \mathrm{~A}$, the rate of increase in current efficiency with further applied current is significantly reduced, with a maximum efficiency of $37 \%$ for the CVD cell and $23 \%$ for the HPHT cell.

The experiment described by Fig. 2b was repeated but with the B sides now connected as the anode, as shown in ESI 4, Fig. S3 and Fig. S4, enabling the effect of surface roughness (ESI 3) on the ozone output gradient and current efficiency to be assessed. The ozone output gradients are identical, within error, for both the CVD and HPHT cells. This is particularly of note for the CVD cell, where the surface roughness varies by more than one order of magnitude, changing from the A to B side in contact with Nafion ${ }^{\circledR}$. With the lapped nucleation face as anode, the ozone output $=3.13 \pm 0.06 \mathrm{mg} \mathrm{L}^{-1} \mathrm{~A}^{-1}$ compared with the as-grown growth face as anode $=3.21 \pm 0.10 \mathrm{mg} \mathrm{L}^{-1} \mathrm{~A}^{-1}$. For the HPHT cell, lapped face as anode, ozone output $=2.23$ 
$\pm 0.07 \mathrm{mg} \mathrm{L}^{-1} \mathrm{~A}^{-1}$ compared with the as-cut face as anode $=2.24 \pm 0.08 \mathrm{mg} \mathrm{L}^{-1} \mathrm{~A}^{-1}$ (surface roughness varying by a factor of $\sim 2$ ). With regards to current efficiency (Figs. S3b and S4b), the trends observed are also very similar. Whilst the smoother surface in the CVD cell shows slightly higher current efficiencies, the reverse is true for the HPHT cell, and thus we observe no obvious dependence of cell performance on electrode surface roughness. If the surface roughness impacts how much of the Nafion ${ }^{\circledR}$ is intimately contacted with the BDD, this data also contrasts with literature which suggests a correlation between contact area of the Nafion ${ }^{\circledR}$ and the electrode and ozone output. ${ }^{14,16}$ All of the UV absorbance data used to calculate dissolved ozone concentrations and corresponding applied current/voltage data are provided in ESI 5, Fig. S5 and Table S1, respectively.

Both CVD and HPHT EOP cells were subject to longer stability tests, with the A sides functioning as the anodes, at an applied current of $0.3 \mathrm{~A}$ for $20 \mathrm{hr}$. The UV absorbance was continually measured, Fig. 3a (CVD) and Fig. 3b (HPHT). To deal with the large volumes of solution required, water from a 10 L reservoir was recirculated through the system (ESI 6, Fig. S6) and electrogenerated ozone removed, prior to recirculation back into the cell, using an inhouse "ozone destroyer" (ESI 6). The large amounts of unavoidable spiking in the UV absorbance data is from the presence of gas bubbles in the flow system, produced during EOP. However, by smoothing the data (solid lines in Figs. 3a,b) it is possible to qualitatively assess the average ozone output over time. For the CVD and HPHT BDD cells, the UV absorbance, and thus dissolved ozone concentration appear relatively constant over the $20 \mathrm{hr}$, reflecting the stability of the two different electrodes on this timescale. 
a)

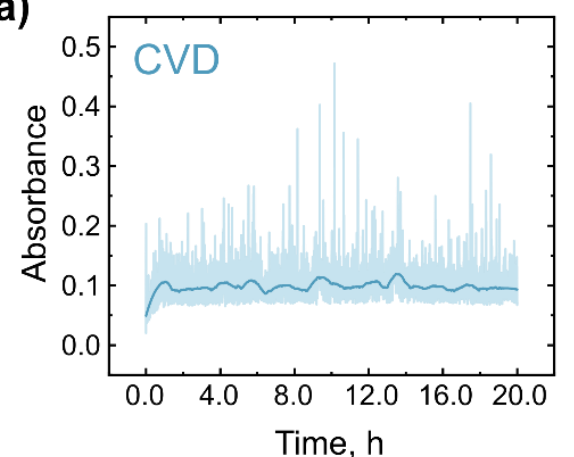

c)

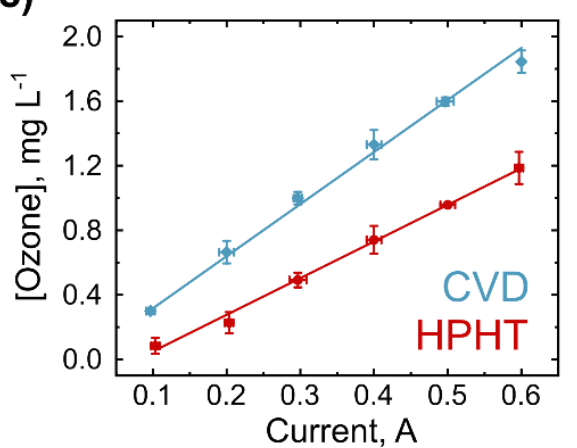

b)

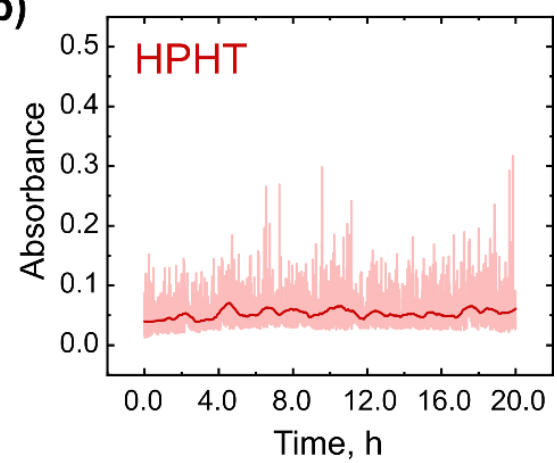

d)

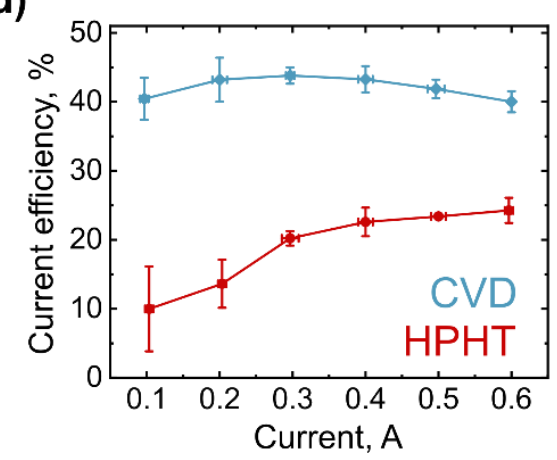

Figure 3: a,b) UV absorbance at $258 \mathrm{~nm}$ over $20 \mathrm{hr}$ with the A side as anode for the a) CVD BDD electrode cell and b) HPHT BDD electrode cell. The flow rates were $194 \pm 1$ and $193 \pm$ $1 \mathrm{~mL} \mathrm{~min}^{-1}$ for the CVD and HPHT cells, respectively. Data was smoothed using a second order polynomial Savitzky-Golay filter with a smoothing window length of 500 points. c,d) Plots to show, after long-term stability testing, c) dissolved ozone concentration and d) current efficiency vs. applied current for the A side anode for the CVD BDD electrode cell (blue line) and the HPHT BDD electrode cell (red line). The flow rates were $324 \pm 4$ and $304 \pm 1 \mathrm{~mL} \mathrm{~min}^{-}$ ${ }^{1}$ for the CVD and HPHT cells, respectively. Error bars represent one standard deviation.

Following the $20 \mathrm{hr}$ long-term stability tests, ozone output calibration plots were again recorded (Fig. 3c) and compared to those in Fig. 2b, recorded prior to these measurements, with the A side functioning as the anode for both the CVD (red line) and HPHT (blue line) cells. For both, the ozone output gradients of the fitted calibration data were largely unaffected by the $20 \mathrm{hr}$ run time i.e., for HPHT $2.23 \pm 0.07 \mathrm{mg} \mathrm{L}^{-1} \mathrm{~A}^{-1}$ (before) versus $2.30 \pm 0.08 \mathrm{mg} \mathrm{L}^{-1}$ $\mathrm{A}^{-1}$ (after) and for CVD $3.13 \pm 0.06 \mathrm{mg} \mathrm{L}^{-1} \mathrm{~A}^{-1}$ (before) versus $3.09 \pm 0.08 \mathrm{mg} \mathrm{L}^{-1} \mathrm{~A}^{-1}$ (after). Both CVD and HPHT calibration plots recorded after the long-term stability test also showed good linearity, with adjusted $\mathrm{R}^{2}$ values of 0.9882 and 0.9817 , respectively. For the CVD cell, 
a slight increase in the ozone output was observed, with the maximum dissolved ozone produced at $0.6 \mathrm{~A}$ increasing to $1.84 \pm 0.07 \mathrm{mg} \mathrm{L}^{-1}$ compared to $1.64 \pm 0.03 \mathrm{mg} \mathrm{L}^{-1}$ after $20 \mathrm{hr}$. For the HPHT cell, the maximum ozone output of $1.19 \pm 0.09 \mathrm{mg} \mathrm{L}^{-1}$ at 0.6 A remained the same, within error. The data in Fig. 3a,b demonstrate that the robustness and long-term EOP performance properties of the HPHT electrodes, over at least a $20 \mathrm{hr}$ period, have not been impaired by the compaction process and they compete favorably with the CVD electrodes.

Fig. 3d shows the current efficiencies of both cells, calculated using eq. 1, after longterm testing. The current efficiency of the HPHT cell is very similar to that observed before long-term testing (Fig. 2c), across the current range investigated, with a maximum current efficiency of $24 \%$ obtained at 0.6 A. Interestingly, for the CVD cell, a slight change in current efficiency response was observed with the response becoming more constant across the full range of applied currents. However, as the maximum current efficiency, ozone output gradient, and maximum ozone output remain the same, we do not believe this change reflects a significant difference in electrode behavior, on this timescale. Measurements were also recorded after the long-term tests but now with the rougher B side electrode functioning as the Nafion®-contacted anode, ESI 7.

In summary, we have proven the efficacy of using compacted HPHT-grown BDD microparticles as a freestanding electrode for the electrochemical generation of dissolved ozone. Compared against the commonly employed CVD grown BDD electrodes, about 30\% less ozone (in $\mathrm{mg} \mathrm{L}^{-1} \mathrm{~A}^{-1}$ ) is produced using the HPHT BDD electrodes. This is attributed primarily to resistances introduced in the HPHT cell system (material and solution) as a consequence of the microparticle compaction process. Further work will look to reduce such effects through optimization of the HPHT synthesis and post synthesis compaction process. The compacted microparticle electrodes are also shown to be robust enough to survive both laser micromachining, mechanical abrasion and the high oxidation potentials of EOP, 
producing dissolved ozone at consistent levels for a continuous $20 \mathrm{hr}$ period with no significant reduction in performance. This study highlights the possibilities that this new class of conducting diamond electrode material, with the additional benefits of potential high-volume production, offers for EOP applications and beyond.

\section{Associated Content}

The Supporting Information is available free of charge at XXXXX.

- Detailed materials and methods for cell fabrication, cell assembly, and experimental setup, including Nafion ${ }^{\circledR}$ membrane pretreatment protocol, electrode surface finishes of cells and WLI images of electrode surfaces

- Raw UV absorbance data and current/voltage data for all experiments

- Additional calibration and current efficiency plots for the B sides of each cell, before and after long-term testing

\section{Author Information}

\section{Corresponding Author}

Julie V. Macpherson - Department of Chemistry, University of Warwick, Coventry CV4 7AL, UK; orcid.org/0000-0002-4249-8383 Email: j.macpherson@warwick.ac.uk

\section{Authors}

Georgia F. Wood - Department of Chemistry and Diamond Science and Technology Centre for Doctoral Training, University of Warwick, Coventry, UK; orcid.org/0000-0002-6695-3491 Irina M. Terrero Rodríguez - Department of Chemistry, University of Warwick, Coventry, UK; orcid.org/0000-0002-3297-8260

Joshua J. Tully - Department of Chemistry, University of Warwick, Coventry, UK; orcid.org/0000-0002-9584-0437 
Shayantan Chaudhuri - Department of Physics and Diamond Science and Technology Centre for Doctoral Training, University of Warwick, Coventry, UK; orcid.org/0000-0003-4299-1837

\section{Author Contributions}

G.F.W and I.M.T.R contributed equally to this work as first authors. G.F.W: Methodology, Validation, Formal analysis, Investigation, Writing - original draft, Visualization. I.M.T.R: Methodology, Validation, Formal analysis, Investigation, Writing - original draft, Visualization. J.J.T: Methodology, Validation, Formal analysis, Investigation, Writing review and editing, Visualization. J.V.M: Conceptualization, Writing - original draft, Visualization, Supervision, Project administration, Funding acquisition. S.C: Software programming for preliminary data collection.

\section{Notes}

The authors declare no competing financial interest.

\section{Acknowledgements}

This work was predominantly supported financially by the EPSRC Impact Acceleration Award grant (EP/R511808/1). G.F.W and S.C were funded by the EPSRC Centre for Doctoral Training in Diamond Science and Technology (EP/L015315/1). I.M.T.R acknowledges funding from the European Union's Horizon 2020 research and innovation program under the Marie Skłodowska-Curie grant agreement no. 813439. J.J.T acknowledges The Royal Society for financial support under the Industry Fellows PhD studentship scheme (INF/PHD/180016). The authors would like to thank Dr. Tim P. Mollart (Element Six), Hossein Zarrin (Element Six), and Prof. Mark. E. Newton (University of Warwick) for many hours of invaluable discussion, and Dana Druka (University of Warwick) for assistance with electrode preparation. The authors would also like to acknowledge the help of Dr. Ben Breeze and the use of Spectroscopy RTP at the University of Warwick, for providing both instrumentation and support. 


\section{References}

(1) Takayama, M.; Ebihara, K.; Stryczewska, H.; Ikegami, T.; Gyoutoku, Y.; Kubo, K.; Tachibana, M. Ozone Generation by Dielectric Barrier Discharge for Soil Sterilization. In Thin Solid Films; Elsevier, 2006; Vol. 506-507, pp 396-399. https://doi.org/10.1016/j.tsf.2005.08.332.

(2) Pan, T. M.; Shimoda, K.; Cai, Y.; Kiuchi, Y.; Nakama, K.; Akimoto, T.; Nagashima, Y.; Kai, M.; Ohira, M.; Saegusa, J.; Kuhara, T.; Maejima, K. Deodorization of Laboratory Animal Facilities by Ozone. Exp. Anim. 1995, 44 (3), 255-259. https://doi.org/10.1538/expanim.44.255.

(3) Gao, M.; Zeng, Z.; Sun, B.; Zou, H.; Chen, J.; Shao, L. Ozonation of Azo Dye Acid Red 14 in a Microporous Tube-in-Tube Microchannel Reactor: Decolorization and Mechanism. Chemosphere 2012, $89 \quad$ (2), 190-197. https://doi.org/10.1016/j.chemosphere.2012.05.083.

(4) Rice, R. G.; Robson, C. M.; Miller, G. W.; Hill, A. G. Uses of Ozone in Drinking Water Treatment. J. / Am. Water Work. Assoc. 1981, 73 (1), 44-57. https://doi.org/10.1002/j.1551-8833.1981.tb04637.x.

(5) Rice, R. G. Applications of Ozone for Industrial Wastewater Treatment - A Review. Ozone: Science and Engineering. Taylor and Francis Inc. 1996, pp 477-515. https://doi.org/10.1080/01919512.1997.10382859.

(6) Devins, J. C. Mechanism of Ozone Formation in the Silent Electric Discharge. J. Electrochem. Soc. 1956, 103 (8), 460. https://doi.org/10.1149/1.2430380.

(7) Christensen, P. A.; Lin, W. F.; Christensen, H.; Imkum, A.; Jin, J. M.; Li, G.; Dyson, C. M. Room Temperature, Electrochemical Generation of Ozone with 50\% Current Efficiency in 0.5M Sulfuric Acid at Cell Voltages \&lt; 3V. Ozone Sci. Eng. 2009, 31 (4), 287-293. https://doi.org/10.1080/01919510903039309.

(8) Wang, Y.-H.; Chen, Q.-Y. Anodic Materials for Electrocatalytic Ozone Generation. Int. J. Electrochem. 2013, 2013, 1-7. https://doi.org/10.1155/2013/128248.

(9) Lukes, P.; Clupek, M.; Babicky, V.; Janda, V.; Sunka, P. Generation of Ozone by Pulsed Corona Discharge over Water Surface in Hybrid Gas-Liquid Electrical Discharge Reactor. J. Phys. D. Appl. Phys. 2005, 38 (3), 409. https://doi.org/10.1088/00223727/38/3/010.

(10) Christensen, P. A.; Yonar, T.; Zakaria, K. The Electrochemical Generation of Ozone: A Review. Ozone: Science and Engineering. Taylor \& Francis Group May 2013, pp 149167. https://doi.org/10.1080/01919512.2013.761564.

(11) Katsuki, N.; Takahashi, E.; Toyoda, M.; Kurosu, T.; Iida, M.; Wakita, S.; Nishiki, Y.; Shimamune, T. Water Electrolysis Using Diamond Thin-Film Electrodes. $J$. Electrochem. Soc. 1998, 145 (7), 2358-2362. https://doi.org/10.1149/1.1838643.

(12) Michaud, P. A.; Panizza, M.; Ouattara, L.; Diaco, T.; Foti, G.; Comninellis, C. Electrochemical Oxidation of Water on Synthetic Boron-Doped Diamond Thin Film Anodes. J. Appl. Electrochem. 2003, $33 \quad$ (2), 151-154. https://doi.org/10.1023/A:1024084924058.

(13) Honda, Y.; Ivandini, T. A.; Watanabe, T.; Murata, K.; Einaga, Y. An Electrolyte-Free System for Ozone Generation Using Heavily Boron-Doped Diamond Electrodes. Diam. Relat. Mater. 2013, 40, 7-11. https://doi.org/10.1016/j.diamond.2013.09.001.

(14) Kraft, A.; Stadelmann, M.; Wünsche, M.; Blaschke, M. Electrochemical Ozone Production Using Diamond Anodes and a Solid Polymer Electrolyte. Electrochem. commun. 2006, 8 (5), 883-886. https://doi.org/10.1016/j.elecom.2006.02.013.

(15) Arihara, K.; Terashima, C.; Fujishima, A. Application of Freestanding Perforated Diamond Electrodes for Efficient Ozone-Water Production. Electrochem. Solid-State 
Lett. 2006, 9 (8), D17. https://doi.org/10.1149/1.2206009.

(16) Arihara, K.; Terashima, C.; Fujishima, A. Electrochemical Production of HighConcentration Ozone-Water Using Freestanding Perforated Diamond Electrodes. $J$. Electrochem. Soc. 2007, 154 (4), E71. https://doi.org/10.1149/1.2509385.

(17) Nishiki, Y.; Kitaori, N.; Nakamuro, K. Performances of Small-Sized Generator of Ozone-Dissolved Water Using Boron-Doped Diamond Electrodes. J. Int. Ozone Assoc. 2011, 33 (2). https://doi.org/10.1080/01919512.2011.549411.

(18) Stucki, S.; Theis, G.; Kötz, R.; Devantay, H.; Christen, H. J. In Situ Production of Ozone in Water Using a Membrel Electrolyzer. J. Electrochem. Soc. 1985, 132 (2), 367-371. https://doi.org/10.1149/1.2113840.

(19) Kitsuka, K.; Kaneda, K.; Ikematsu, M.; Iseki, M.; Mushiake, K.; Ohsaka, T. N-Type $\mathrm{TiO}[\mathrm{Sub} 2]$ Thin Films for Electrochemical Ozone Production. J. Electrochem. Soc. 2010, 157 (2), F30. https://doi.org/10.1149/1.3265469.

(20) Wang, Y.-H.; Cheng, S.; Chan, K.-Y.; Li, X. Y. Electrolytic Generation of Ozone on Antimony- and Nickel-Doped Tin Oxide Electrode. J. Electrochem. Soc. 2005, 152 (11), D197. https://doi.org/10.1149/1.2041007.

(21) Angus, J. C.; Will, H. A.; Stanko, W. S. Growth of Diamond Seed Crystals by Vapor Deposition. J. Appl. Phys. 1968, 39 (6), 2915-2922. https://doi.org/10.1063/1.1656693.

(22) May, P. W.; Mankelevich, Y. A. From Ultrananocrystalline Diamond to Single Crystal Diamond Growth in Hot Filament and Microwave Plasma-Enhanced CVD Reactors: A Unified Model for Growth Rates and Grain Sizes. J. Phys. Chem. C 2008, 112 (32), 12432-12441. https://doi.org/10.1021/jp803735a.

(23) Chaplin, B. P.; Wyle, I.; Zeng, H.; Carlisle, J. A.; Farrell, J. Characterization of the Performance and Failure Mechanisms of Boron-Doped Ultrananocrystalline Diamond Electrodes. J. Appl. Electrochem. 2011, 41 (11), 1329-1340. https://doi.org/10.1007/s10800-011-0351-7.

(24) Stanic, V.; Hoberecht, M. Mechanism of Pinhole Formation in Membrane Electrode Assemblies for PEM Fuel Cells. In Proceedings - Electrochemical Society; IOP Publishing, 2004; Vol. PV 2004-21, pp 391-401. https://doi.org/10.1149/200421.0391pv.

(25) Handschuh-Wang, S.; Wang, T.; Tang, Y. Ultrathin Diamond NanofilmsDevelopment, Challenges, and Applications. Small. 2021. https://doi.org/10.1002/smll.202007529.

(26) Survey, U. S. G. Mineral Commodity Summaries 2019. Miner. Commod. Summ. 2019, 54. https://doi.org/10.3133/70202434.

(27) Kiflawi, I.; Kanda, H.; Lawson, S. C. The Effect of the Growth Rate on the Concentration of Nitrogen and Transition Metal Impurities in HPHT Synthetic Diamonds. Diam. Relat. Mater. 2002, 11 (2), 204-211. https://doi.org/10.1016/S09259635(01)00569-6.

(28) Wood, G. F.; Zvoriste-Walters, C. E.; Munday, M. G.; Newton, M. E.; Shkirskiy, V.; Unwin, P. R.; Macpherson, J. V. High Pressure High Temperature Synthesis of Highly Boron Doped Diamond Microparticles and Porous Electrodes for Electrochemical $\begin{array}{llllll}\text { Applications. } & \text { Carbon } & \text { 2021, } & \text { Y } & \text { 171, } & \text { 845-856. }\end{array}$ https://doi.org/10.1016/j.carbon.2020.09.038.

(29) Hutton, L.; Newton, M. E.; Unwin, P. R.; Macpherson, J. V. Amperometric Oxygen Sensor Based on a Platinum Nanoparticle-Modified Polycrystalline Boron Doped Diamond Disk Electrode. Anal. Chem. 2008, 81 (3), 1023-1032. https://doi.org/10.1021/AC8020906.

(30) Cobb, S. J.; Laidlaw, F. H. J.; West, G.; Wood, G.; Newton, M. E.; Beanland, R.; Macpherson, J. V. Assessment of Acid and Thermal Oxidation Treatments for 
Removing Sp2 Bonded Carbon from the Surface of Boron Doped Diamond. Carbon N. Y. 2020, 167, 1-10. https://doi.org/10.1016/j.carbon.2020.04.095.

(31) Hutton, L. A.; Iacobini, J. G.; Bitziou, E.; Channon, R. B.; Newton, M. E.; Macpherson, J. V. Examination of the Factors Affecting the Electrochemical Performance of OxygenTerminated Polycrystalline Boron-Doped Diamond Electrodes. Anal. Chem. 2013, 85 (15), 7230-7240. https://doi.org/10.1021/ac401042t. 